\title{
EDITORIAL
}

\section{Implications of the FAST Protocol Beyond Spirituality}

\author{
Jonathan G. Gabison, MD \\ Department of Family Medicine, University of Michigan, Ann Arbor, Michigan
}

Ann Fam Med 2020;18:98-99. https://doi.org/10.1370/afm.2496.

$\mathrm{F}$ asting for spiritual purposes is widely practiced and remains part of virtually every major religion in the world. The Fasting Algorithm for Singaporeans with Type 2 Diabetes (FAST) protocol opens the door to a safe approach to fasting for Islamic patients who observe Ramadan, and its application can extend beyond Islamic patients to patients of other religions. The study by Lee et al ${ }^{1}$ demonstrates that persons with type 2 diabeties can, with the help of their physicians, engage in safe fasting practices, and they can attain positive health benefits while doing so in the form of improved hemoglobin $\mathrm{A}_{1 \mathrm{C}}$ and fasting blood glucose (FBG) levels. Moreover, when observing the FAST protocol, patients are less likely to avoid their doctors and have an improved therapeutic relationship with the medical community in their time of spiritual work.

The implications of this study also extend beyond fasting for spiritual reasons. People with or without diabetes are more frequently engaging in the practice of fasting. Individuals are recommended to fast before surgery or procedures like colonoscopies. Although a controversial topic in the medical and nutritional community, patients, including those with type 2 diabetes, are increasingly using it as a strategy for weight loss or health benefits. Fasting regimens can range from timerestricted feeding, to alternate-day or whole-day fasts.

Recent studies have shown that fasting regimens have reduced body weight, body fat, total cholesterol, and triglycerides in normal weight, overweight, and obese humans. Reductions in low-density lipoproteins (LDL) and blood pressure, and increases in LDL particle size have also been seen in some studies. ${ }^{2}$ Fourteen to 36 hours of fasting has also been shown to increase resting energy expenditure and basal metabolic rate. ${ }^{3}$

Conflicts of interest: author reports none.

\section{CORRESPONDING AUTHOR}

Jonathan G. Gabison, MD

Department of Family Medicine

University of Michigan

8101 Briarwood Cir

Ann Arbor, MI 48108

gabisonj@med.umich.edu
In diabetic patients, fasting has been shown to lower fasting insulin and fasting glucose and to have positive overall effects on an individual's hemoglobin $\mathrm{A}_{1 \mathrm{c}}{ }^{4}$ Long-term fasting schedules have even been shown to reverse type 2 diabetes in certain case studies series. ${ }^{5}$

Similarly, many individuals are attempting low carbohydrate diets (LCD) to obtain health benefits. LCD intervention has shown significant improvement in glycemic control in patients with type 2 diabetes, as well as having positive effects on triglycerides and high-density lipoproteins HDL cholesterol. ${ }^{6}$ Diabetic patients using diabetes medications should take care when practicing an LCD to avoid hypoglycemic events, and recent guidelines from the National Lipid Association Nutrition and Lifestyle Taskforce recommended close physician supervision for such patients. ${ }^{7}$ Diabetic patients who desire to lose weight and have considered an LCD could be another group to benefit from the FAST protocol, which could allow physicians to better support such patients.

While more research is needed, a protocol to manage diabetes medications safely with intermittent fasting may help keep patients safe while we learn more about the use of these strategies to help combat obesity and diabetes. We now know that it is possible for physicians who have a good knowledge of the pharmacology of various diabetes medication classes to support patients who decide to change their eating behaviors, whether via fasting or low-carbohydrate diets.

To read or post commentaries in response to this article, see it online at http://www.AnnFamMed.org/content/18/2/98.

Submitted November 11, 2019; accepted November 11, 2019.

Key words: fasting; food deprivation; time-restricted feeding; diabetes mellitus, type 2

\section{References}

1. Lee JY, Khoo Z, See Toh W, et al. Efficacy and safety of use of the Fasting Algorithm for Singaporeans With Type 2 Diabetes (FAST) during Ramadan: a prospective, multicenter, randomized controlled trial. Ann Fam Med. 2020:18(2):139-147.

2. Tinsley GM, La Bounty PM. Effects of intermittent fasting on body composition and clinical health markers in humans. Nutr Rev. 2015; 73(10):661-674. 
3. Zauner C, Schneeweiss B, Kranz A, et al. Resting energy expenditure in short-term starvation is increased as a result of an increase in serum norepinephrine. Am J Clin Nutr. 2000;71(6):1511-1515.

4. Carter S, Clifton PM, Keogh JB. Effect of intermittent compared with continuous energy restricted diet on glycemic control in patients with type 2 diabetes: a randomized noninferiority trial. JAMA Netw Open. 2018;1(3):e180756.

5. Furmli S, Elmasry R, Ramos M, Fung J. Therapeutic use of intermittent fasting for people with type 2 diabetes as an alternative to insulin. BMJ Case Rep. 2018. pii: bcr-2017-221854.
6. Meng Y, Bai H, Wang S, Li Z, Wang Q, Chen L. Efficacy of low carbohydrate diet for type 2 diabetes mellitus management: a systematic review and meta-analysis of randomized controlled trials. Diabetes Res Clin Pract. 2017;131:124-131.

7. Kirkpatrick CF, Bolick JP, Kris-Etherton PM. Review of current evidence and clinical recommendations on the effects of lowcarbohydrate and very-low-carbohydrate (including ketogenic) diets for the management of body weight and other cardiometabolic risk factors: a scientific statement from the National Lipid Association Nutrition and Lifestyle Task Force. J Clin Lipidol. 2019. pii: S1933-2874(19)30267-3.

\section{Thank You, Reviewers and E-Letter Contributors!}

Ann Fam Med 2020;18:99. https://doi.org/10.1370/afm.1923.

W e would like to thank two groups who provide important insights to the Annals of Family Medicine.

Peer reviewers are key to advancing scholarship and contributing to the quality of a research journal. We are grateful to the many individuals who contribute their time and expertise to the review process. Please see http://www.AnnFamMed.org/site/misc/reviewers19. xhtml for the names of the Annals' 2019 peer reviewers.
The Annals is also enriched by those who contribute e-letters. In 2019, we posted many e-letters reflecting on a wide range of published articles. Our sincere thanks to those who participated in this stimulating dialogue. To read e-letters, click on "View comments" on the right-hand side of any article or visit http://www.AnnFamMed.org/ and click on "TRACK Discussion." 